\title{
Synthesis and biological evaluation of Combretastatin A-4 derivatives containing a 3'-O-substituted carbonic ether moiety as potential antitumor agents
}

\author{
Mingyi Ma, Longru Sun ${ }^{*}$, Hongxiang Lou and Mei Ji
}

\begin{abstract}
Background: Combretastatin A-4 (CA-4), which is an excellent antineoplastic agent, was isolated from Combretum caffrum. To date, structural modification studies of CA-4 have focused predominantly on the construction of new therapeutic agents for drug discovery. As a part of our ongoing work towards the modification of natural products, we have focused on the 3'-O-substituent groups in the B-ring of CA-4 under the hypothesis that these novel derivatives will possess good bioactivities and behave as effective antiproliferative pro-drugs.

Results: A series of novel CA-4 derivatives, which contained a 3'-O-substituted carbonic ether moiety, were synthesized and evaluated for their antitumor activities against four tumor cell lines, including MDA-MB-231, MCF-7, K562 and A549 cells. These derivatives exhibited clear antitumor activities, and CA-4E, in particular, showed the highest bioactivity of all of the derivatives tested against all four tumor cell lines, with $I C_{50}$ values in the range of 1 to $180 \mathrm{nM}$. Based on its high bioactivity, CA-4E was subsequently selected to investigate the antitumor mechanism of these synthetic compounds. The cell cycle results demonstrated that CA-4E induced time- and dose-dependent G2/M arrest in a similar manner to CA-4, although its effect was more powerful than that of CA-4, and the apoptosis data showed that CA-4E induced cellular apoptosis in a dose-dependent manner.

Conclusions: The newly synthesized CA-4 derivatives exhibited good antitumor activities in vitro, with CA-4E, in particular, showing the highest bioactivity of all of the compounds tested. Furthermore, CA-4E induced time- and dose-dependent G2/M arrest and cellular apoptosis in a dose-dependent manner. Taken together, these results suggest that CA-4E should be subjected to further investigation as a potential anticancer drug candidate.
\end{abstract}

Keywords: Combretastatin A-4, Synthesis, Antitumor activity, WST-1, Cell cycle arrest, Apoptosis

\section{Background}

Combretastatin A-4 (CA-4, Figure 1) is a natural product, which was first isolated from the bark of the South African tree Combretum caffrum by Pettit et al. in 1989 [1]. As a potentially effective vascular disrupting agent (VDA), CA-4 can discriminate between normal vessels and tumor vessels and selectively disrupt the abnormal tumor vasculature, leading ultimately to vascular collapse [2-4]. Furthermore, CA-4 exhibits excellent anticancer properties by interfering

\footnotetext{
* Correspondence: sunlr@sdu.edu.cn

Department of Natural Products Chemistry, Key Lab of Chemical Biology (MOE), School of Pharmaceutical Sciences, Shandong University, No. 44 West
} Wenhua Road, Jinan 250012, PR China with the dynamics of tubulin, in that CA-4 inhibits the polymerization of tubulin by binding to the colchicine site, which results in cell mitotic arrest [5]. The activity of the trans isomer of CA-4 (Figure 1), however, is much lower than that of CA-4. For example, CA-4 displays cytotoxicity at low nanomolar concentrations, whereas the trans isomer inhibits cell growth in the micromolar range [6].

CA-4 has recently been the subject of considerable interest from pharmaceutical chemists attempting to design new compounds capable of mimicking the bioactivity of CA-4, and a wide variety of analogues and derivatives of CA-4 have been synthesized and evaluated for their antitumor activities in vitro. Based on these derivatives, 


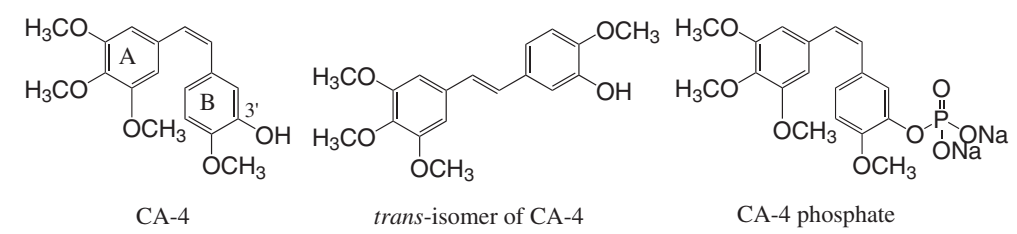

Figure 1 Structures of $C A-4$, the trans isomer of CA-4 and CA-4 phosphate.

several structure-activity relationships (SARs) have been identified for CA-4, which are summarized in Figure 2. These SARs have demonstrated that the 3,4,5-trimethoxysubstituted A-ring and the cis configuration of the stilbene connecting the A-ring to the B-ring are both essential to the antiproliferative activity of these compounds [7-9]. The 3'-hydroxy group of B-ring has been shown to be non-essential for the interaction of CA-4 with tubulin, and this particular moiety could potentially be replaced with other suitable substituents [10]. A series of CA-4 derivatives bearing different substituents at the 3'-position of the B-ring, such as a halogen atom (e.g., fluorine or bromine), amine, boronic acid, nitro, amide, alkoxy or acyl group, were synthesized and evaluated for their antitumor activities [11-13]. Among these derivatives, a water soluble pro-drug of CA-4, CA-4 phosphate (CA-4P, Figure 1), was identified and progressed into clinical trials as a potential vascular disrupting agent that could be used in combination with conventional cytotoxic therapies for the treatment of cancer [14]. With this in mind, and as part of our ongoing work towards the synthesis of natural product derivatives with interesting biological properties, we have focused our attention on modifying the 3'-O-substituent groups in the B-ring of CA-4. It is envisaged that these novel derivatives would posses good bioactivities compared to CA-4, and that they could be used as potential antiproliferative pro-drugs. Herein, we describe the design, synthesis and evaluation of the cytotoxicity of a series of novel Combretastatin A-4 derivatives. Furthermore, the most active of these compounds, CA-4E, was selected to investigate the antitumor mechanism of this novel series of compounds.

\section{Results and discussion Chemistry}

CA-4 is recognized as an important parent compound, in terms of its biological effects, and hundreds of structural modified CA-4 derivatives have been synthesized and reported $[15,16]$, where the modifications have traditionally been affected using either a Wittig reaction or a Perkin condensation reaction. Using the Wittig reaction, the CA-4 product is generally formed as a mixture with the corresponding trans isomer, which can be difficult to remove, and this can lead to complications in any follow-up work [17]. In contrast, the
Perkin condensation proceeds stereoselectively to afford CA-4 as the major product [18]. The use of the Perkin condensation reaction therefore provides better access to the CA-4 derivatives and, in contrast to the Wittig reaction, does not require extensive purification procedures.

Our synthetic route to the CA-4 derivatives is depicted in Scheme 1 (Additional file 1), where the parent compound CA-4 was prepared via a Perkin condensation following a previously described procedure [18]. A mixture of 3,4,5-trimethoxyphenylacetic acid (1), 3-hydroxy-4methoxybenzaldehyde (2), triethylamine, and acetic anhydride was heated at reflux at $140^{\circ} \mathrm{C}$ to give intermediate 3. The reaction mixture was then hydrolyzed using sodium hydroxide, and the cinnamic acid analogue 4 was precipitated from the solution following acidification with concentrated hydrochloric acid. Subsequent purification of the crude precipitate by recrystallization from ethanol gave pure $\mathbf{4}$ in $65 \%$ yield. Compound $\mathbf{4}$ was then decarboxylated with copper powder in quinoline at $220^{\circ} \mathrm{C}$, and the crude product was purified by flash column chromatography (FCC) to give CA-4 in $55 \%$ yield together with a very small amount of its trans isomer. The CA-4 derivatives 6-14, which contained an O-substituted carbonic ether moiety, were prepared via the acylation of CA-4 with the chloroformic acid alkyl esters $\mathbf{5}$ and pyridine, and the crude derivatives were purified by FFC. All of the newly synthesized compounds were characterized using their spectra data (Additional file 2).

\section{Biological activity evaluation}

WST-1-based cell cytotoxicity assay

The in vitro cytotoxicities of the synthesized compounds were evaluated against selected human cancer

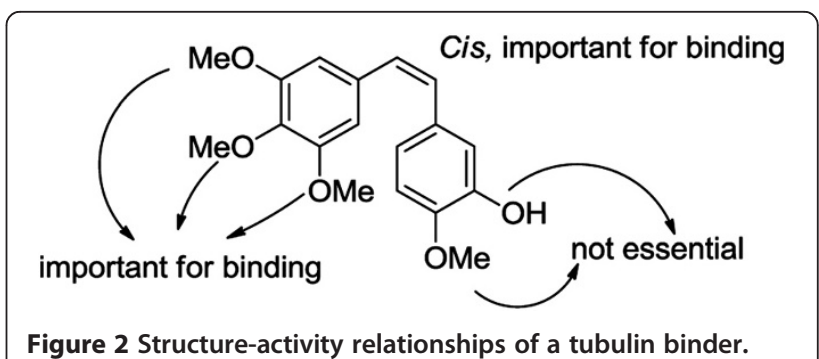




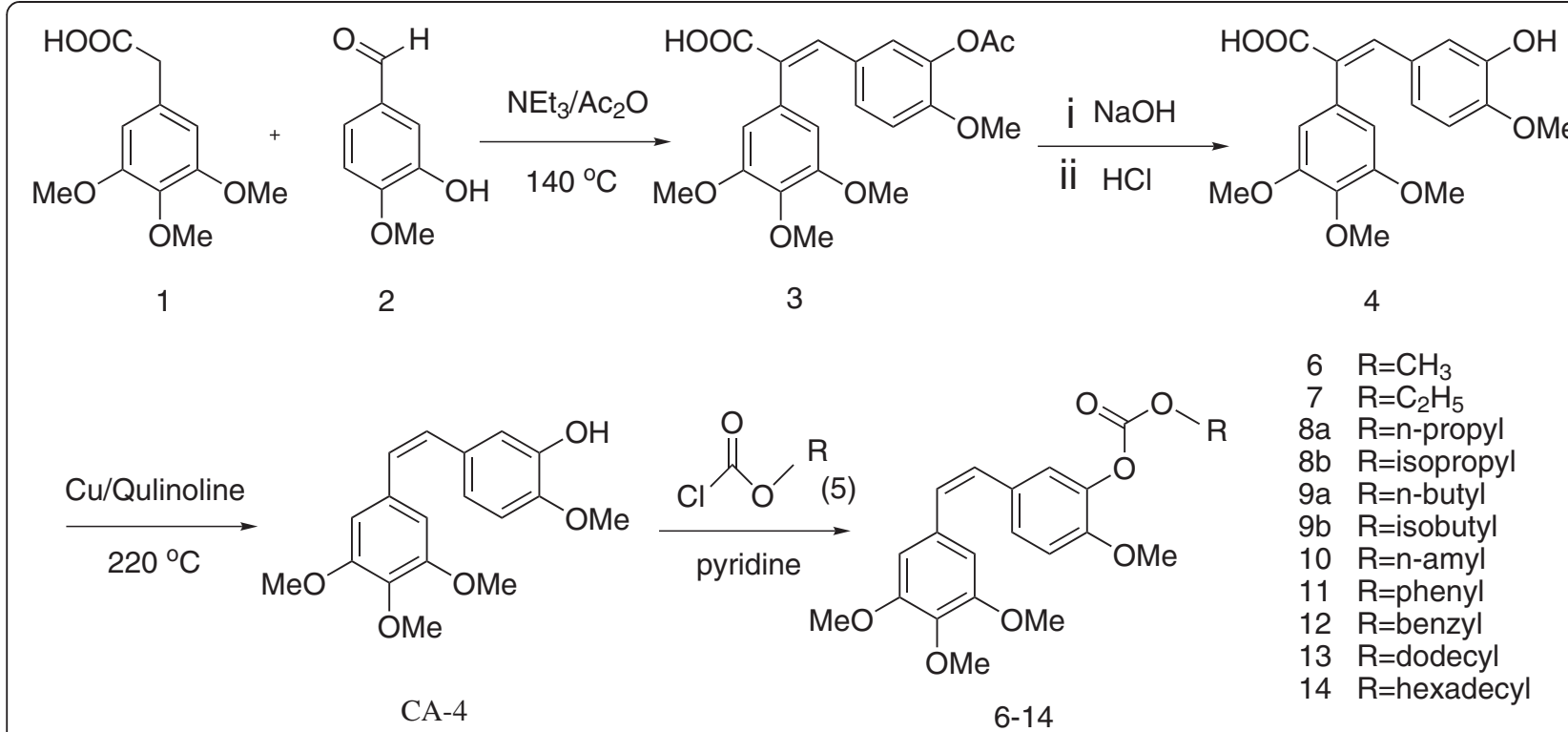

Scheme 1 Synthetic route to CA-4 and the target compounds 6-14.

cell lines for breast (MDA-MB-231 and MCF-7), lung (A549) and leukemia (K562) using a WST-1-based colorimetric cell cytotoxicity assay [19]. All of the experiments were performed in triplicate. The WST-1based assay was used in the current study instead of the MTT-based assay because it is generally considered to be more rapid, sensitive and accurate than the MTT assay. Furthermore, this assay involves the detection of water-soluble formazan, and therefore does not require an additional solubilization step [19]. The absorbance was measured on a microplate reader at $450 / 630 \mathrm{~nm}$ with CA-4 being used as a positive control. The corresponding $\mathrm{IC}_{50}$ values were calculated and are listed in Table 1.

As shown in Table 1, all of the synthesized compounds exhibited good in vitro cytotoxicity against all four of the tumor cell lines tested, with $\mathrm{IC}_{50}$ values of less than $800 \mathrm{nM}$ in all cases, except for compound 14. Compound 7 (CA-4E) showed the greatest cytotoxicity of all of the compounds tested against all four cell lines with $\mathrm{IC}_{50}$ values in the range of 1 to $180 \mathrm{nM}$. It is noteworthy that CA-4E showed lower cytotoxicities than those of CA-4. Compound 6 was only weakly cytotoxic compared to CA-4, except against the MCF-7 cells. Compounds 8a, 8b, 9a, 9b, 10, 11 and 12 displayed similar cytotoxicities to the parent compound CA-4 against the MDA-MB-231, MCF-7 and A549 cells. However, compounds 13 and 14, especially 14, showed much lower cytotoxicities than CA-4, and these lower cytotoxicities were attributed to the size of the 3'-O-substituted carbonic ether moiety, in that the long side chain in $\mathbf{1 4}$ most likely prevented the binding of the active moiety to the colchicine site of tubulin. These results therefore suggested that the modification of CA-4 with bulky substituents at the C-3' position would lead to a reduction in the activity of the inhibitors.

Table 1 In vitro cytotoxicities against four different tumor cell lines

\begin{tabular}{lcccc}
\hline Compound & \multicolumn{4}{c}{$\mathbf{I C}_{\mathbf{5 0}}$ (nM) } \\
\cline { 2 - 5 } & MDA-MB-231 & MCF-7 & K562 & A549 \\
\hline CA-4 & 6.27 & 10.49 & 5.75 & 428 \\
$\mathbf{6}$ & 12.29 & 8.00 & 7.68 & 693 \\
$\mathbf{7}($ CA-4E) & 2.30 & 1.32 & $<2.50$ & 180 \\
$\mathbf{8 a}$ & 7.26 & 8.38 & 14.78 & 486 \\
$\mathbf{8 b}$ & 7.77 & 7.59 & 14.88 & 476 \\
$\mathbf{9 a}$ & 7.94 & 10.04 & 14.90 & 309 \\
$\mathbf{9 b}$ & 6.68 & 11.29 & 8.76 & 330 \\
$\mathbf{1 0}$ & 6.40 & 10.39 & 9.42 & 435 \\
$\mathbf{1 1}$ & 4.39 & 12.46 & 12.28 & 316 \\
$\mathbf{1 2}$ & 7.27 & 7.09 & 8.85 & 265 \\
$\mathbf{1 3}$ & 12.23 & 10.85 & 9.65 & 735 \\
$\mathbf{1 4}$ & 39.60 & 66.09 & 80.84 & $>1000$ \\
\hline
\end{tabular}


Several CA-4 derivatives bearing similar substituents to those of CA-4E at the 3'-position of their B-ring, such as a hydroxyethyl (15), chloroethyl (16), acetyl (17), methyl (18) or chloroethyl-carbamoyl (19) group (Figure 3), were synthesized and evaluated for their antitumor activity. As previously reported, compounds 15, 16 and 19 exhibited very low levels of cytotoxicity against the tumor cell lines tested (i.e., SK-N-SH, SW1736, NCI-H460, DU-145 and FADU cells), with $\mathrm{IC}_{50}$ values in the range of 28 to 4,700 $\mathrm{nM}$, whereas CA-4 exhibited $\mathrm{IC}_{50}$ values in the range of 0.26 to $0.76 \mathrm{nM}$ against the same cell lines [13]. Compound 17 displayed similar cytotoxicity to CA-4 against the murine leukemic cell line $\mathrm{L} 1210$, with an $\mathrm{IC}_{50}$ value of $7 \times 10^{3} \mathrm{nM}$, whereas compound $\mathbf{1 8}$ gave an $\mathrm{IC}_{50}$ value of $3 \times 10^{5} \mathrm{nM}$ against the same cell line [20]. Taken together, these results clearly demonstrate that CA-4E exhibited higher levels of cytotoxicity than CA-4 against all four of the tumor cell lines tested. Further studies would be required, however, to determine whether the additional activity of CA-4E was due to its carbonic acid ester (CA-4E) or decomposition products, and potentially develop a clinical useful anticancer agent.

\section{Cell cycle analysis}

In light of its remarkable antitumor activity, CA-4E was selected as being the best representative of the synthesized compounds and its antitumor effects on the cell cycle were investigated further and compared to those of CA-4. MCF-7 cells were treated with 1.5 and $3 \mathrm{nM}$ of CA- 4 and CA-4E for 24 and $36 \mathrm{~h}$, respectively. The cells were then analyzed by FCM, and the results are shown in Figure 4. The G1 phase frequencies were 75.09, 65.05 and 58.26\% after treatment with $0,1.5$, and $3 \mathrm{nM}$ of CA- 4 for $24 \mathrm{~h}$, respectively. Furthermore, the treatment of the MCF-7 cells with $0,1.5$, and $3 \mathrm{nM}$ of CA-4E led to G1 phase frequencies of $75.09,61.44$ and $39.64 \%$, respectively. The results illustrated that treatment with CA-4 or CA-4E led to similar reductions in the number of cells in the G1 phase, and the effect of CA-4E was more pronounced, especially at the higher concentration. The frequencies of cells in the G2/M phase following treatment with $0,1.5$, and $3 \mathrm{nM}$ of CA-4 were $0.74,4.54$ and $7.92 \%$, respectively, whereas treatment with the same concentration of CA-4E gave $\mathrm{G} 2 / \mathrm{M}$ frequencies of $0.74,7.74$ and $24.61 \%$, respectively.
These results indicated that CA-4 and CA-4E both led to a concentration-dependent increase in the number of cells in the G2/M phase, with the effect of CA-4E being more pronounced than that of CA-4, especially at the higher concentration. Similar results were also observed for the cells cultured for $36 \mathrm{~h}$, except the number of cells in the $\mathrm{S}$ phase increased after culturing for $24 \mathrm{~h}$, whereas a decrease was observed after culturing for $36 \mathrm{~h}$. These results demonstrated that CA-4E induced the transfer of the cell arrest phase from the G1 phase to the G2/M phase via the $S$ phase. These cell cycle analysis experiments demonstrated that CA-4E induced both time- and dosedependent $\mathrm{G} 2 / \mathrm{M}$ arrest in the same way as $\mathrm{CA}-4$, but more powerfully.

\section{Effect on apoptosis}

The effect of CA-4E on the apoptosis of MCF-7 cells was also evaluated. MCF-7 cells were exposed to different concentrations of CA-4E for $24 \mathrm{~h}$, and the FITC-Annexin V/PI double staining method for FCM was used to construct apoptotic cell scatter plots. The results are shown in Figure 5 (A). The apoptotic cell scatter plot was divided into four quadrants, including the B1 quadrant, which represents the damaged cells; B2 quadrant, which represents late apoptotic cells; B3 quadrant representing living cells; and B4 quadrant, which represents early apoptotic cells. The cells in the B2 and B4 quadrants were regarded as apoptotic cells, and were used to evaluate the effect of CA-4E on apoptosis. The total percentages of apoptotic cells were 2.84, 8.74, 12.34 and $33.03 \%$ at concentrations of $0,1.5,3$ and $6 \mathrm{nM}$, respectively. As shown in Figure 5 (B), the rate of apoptosis increased sharply with increasing CA-4E concentration. This result demonstrated that CA-4E induced cellular apoptosis in a dose-dependent manner.

\section{Experimental section \\ Chemistry}

FCC was performed with 200-300 mesh silica gel (10$40 \mu \mathrm{m}$, Qingdao Haiyang Chemical Co. Ltd., Qingdao, China). The reactions were monitored by thin-layer chromatography using silica gel $\mathrm{GF}_{254}$ plates (Qingdao Haiyang Chemical Co. Ltd.), and the plates were visualization by UV light. Melting points were measured on a Gallenkamp

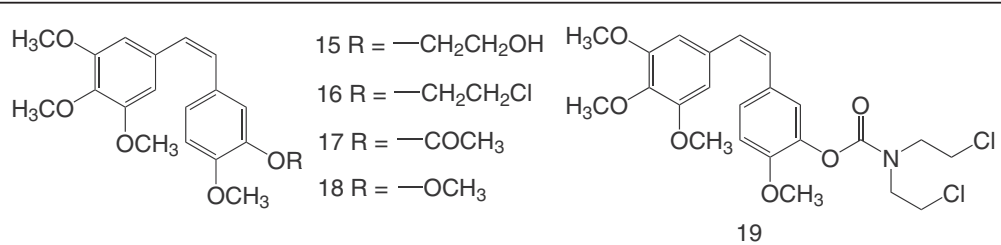

Figure 3 Structures of the CA-4 derivatives. 


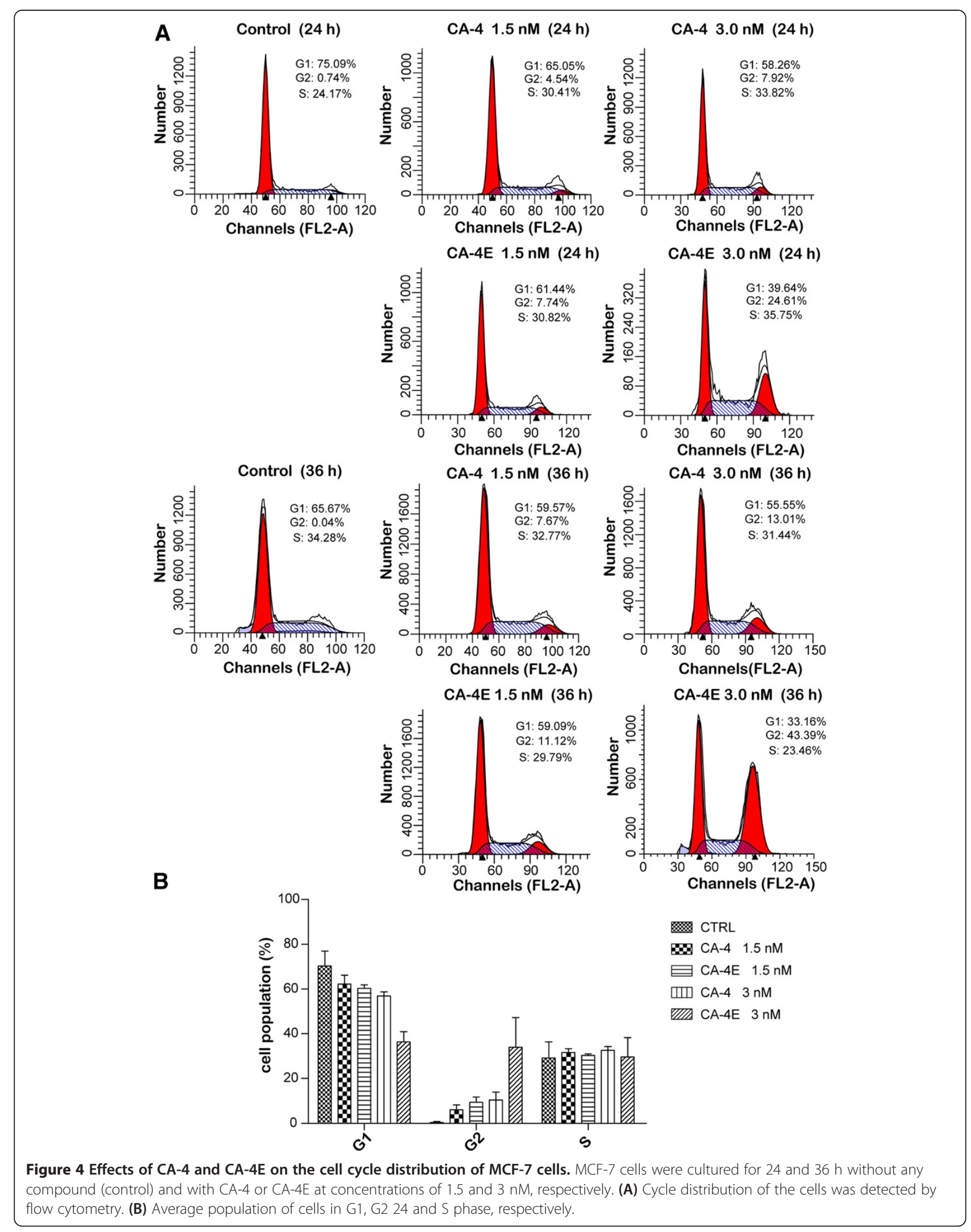



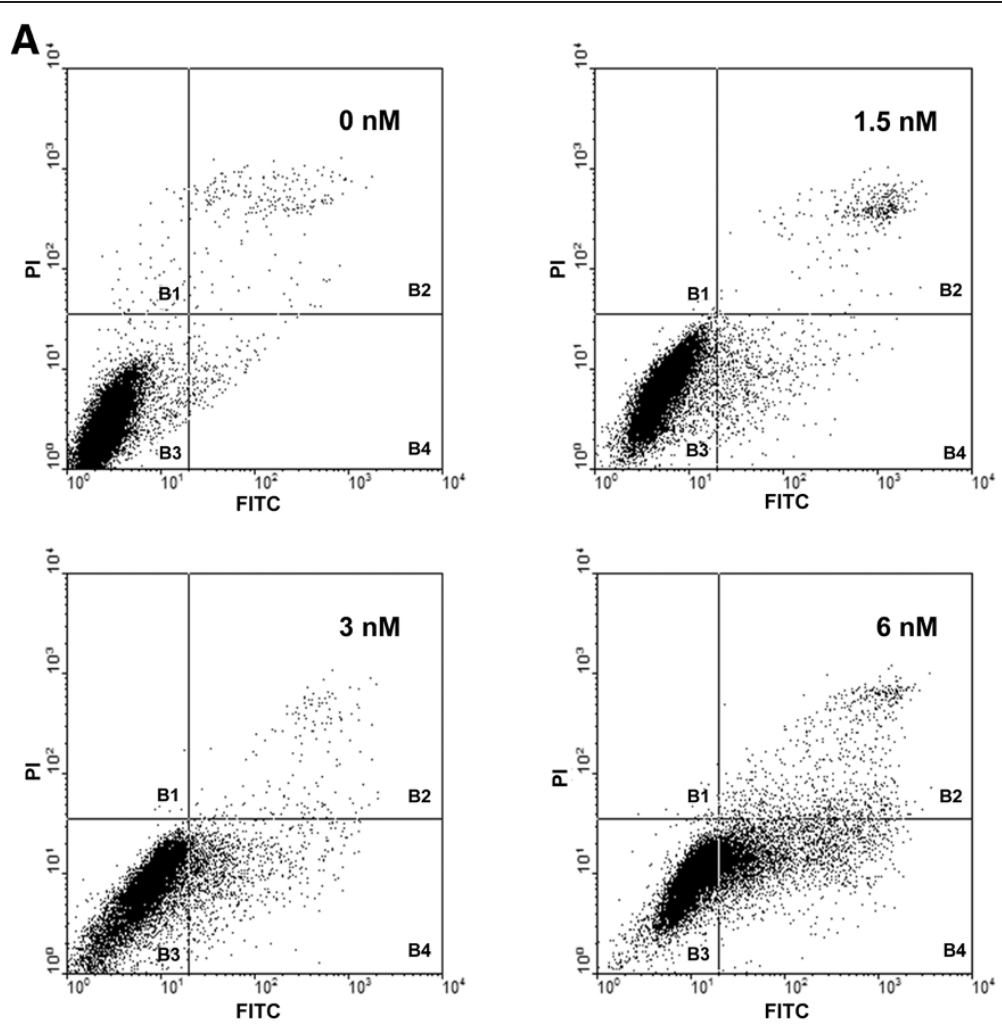

B

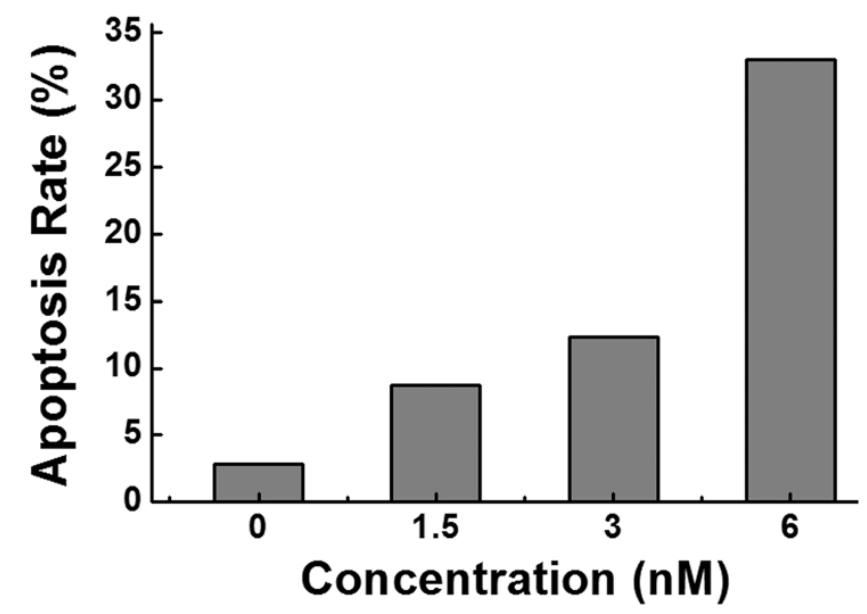

Figure 5 Apoptotic effect on MCF-7 cell line induced by CA-4E. MFC-7 cells were incubated in media containing various concentrations of CA-4E (i.e., 0, 1.5, 3 and 6 nM) for 24 h. (A) Apoptotic cell scatter plots were constructed by flow cytometry using FITV-Annexin V/PI staining. (B) Rate of apoptotic cells at different concentrations of CA-4E.

melting point apparatus (Beijing, China). NMR spectra were recorded on a Bruker Avance $300 \mathrm{MHz}$ NMR spectrometer (Bruker, Billerica, Massachusetts, USA) at 300 $\left({ }^{1} \mathrm{H}\right)$ and $75\left({ }^{13} \mathrm{C}\right) \mathrm{MHz}$ using TMS as an internal reference standard. HRMS were conducted on an LTQQrbitrap XL (Thermo-Fisher, Cambridge, Massachusetts, USA). The experimental procedures for preparation of CA-4 and the target compounds 6-14, as well as copies of ${ }^{1} \mathrm{H}$-NMR and ${ }^{13} \mathrm{C}$-NMR, can be found in Additional file 2.

\section{Biological activity evaluation}

\section{Cell culture and antitumor activity}

Four human tumor cell lines were tested in the current study, including MDA-MB-231 breast cancer, MCF-7 breast cancer, K562 leukemia, A549 lung cancer cells, which were obtained from the Immune Pharmacological Research Institute at Shandong University. All of the test compounds were dissolved in DMSO at $10 \mu \mathrm{M}$, and subsequently diluted to the appropriate concentration prior 
to the addition to the cells. All four human tumor cell lines were cultured in an RPMI 1640 medium (GIBCO) supplemented with $10 \%$ bovine fetal calf serum. The cell lines were maintained at $37^{\circ} \mathrm{C}$ in a humidified atmosphere containing $5 \% \mathrm{CO}_{2}$ in an incubator. The cancer cells were seeded in 96-well plates and treated with different concentrations of the synthesized compounds after $6 \mathrm{~h}$ of incubation. Five replicate wells were used for each concentration, and the concentration of DMSO used in each case never exceeded $0.1 \%$, so that it would not affect the growth of the cells. The treated cells were incubated for $72 \mathrm{~h}$ and $10 \mu \mathrm{L}$ of the cell proliferation reagent WST-1 was then added to each well. The wells were then incubated at $37^{\circ} \mathrm{C}$ under $5 \% \mathrm{CO}_{2}$ in a humidified incubator for $2 \mathrm{~h}$. The absorbance was measured in a microplate reader at $450 / 630 \mathrm{~nm}$. The $\mathrm{IC}_{50}$ values were then calculated according to the percentage of growth in the presence of the test compounds.

\section{Cell cycle analysis}

For the cell cycle analysis experiments, MCF-7 cells $\left(3 \times 10^{5}\right)$ were seeded in 6-well plates and treated with different concentrations of CA-4 and CA-4E (i.e., 0, 1.5, and $3 \mathrm{nM}$ ). The cells were then incubated for 24 and $32 \mathrm{~h}$ before being washed twice with ice-cold PBS, harvested, fixed with ice-cold PBS in $75 \%$ ethanol and stored at $4{ }^{\circ} \mathrm{C}$ overnight. The cells were then incubated with RNase A $(0.1 \mathrm{mg} / \mathrm{mL})$ at $37^{\circ} \mathrm{C}$ for $45 \mathrm{~min}$, and then stained with propidium iodide $(0.1 \mathrm{mg} / \mathrm{mL})$ for $30 \mathrm{~min}$ on ice in the absence of light. The DNA contents of 10,000 events were measured by flow cytometery and the cell cycle profiles were analyzed on the basis of the DNA content histograms [21].

\section{Cell apoptosis with FITC-Annexin V/PI double staining}

Trypsin without EDTA was used to digest and collect the control group and the cells treated with 1.5 and $3 \mathrm{nM}$ of CA-4 and CA-4E. Flow cytometry was performed according to the manufacturer's procedure provided with the apoptosis detection kit. The MCF-7 cells were washed twice with PBS and centrifuged at $650 \times \mathrm{g}$ for $5 \mathrm{~min}$. A binding buffer suspension $(500 \mu \mathrm{L})$ was added to the cells followed by $5 \mu \mathrm{L}$ of the FITC-Annexin $\mathrm{V}$ mix, and the resulting mixture was held at $4^{\circ} \mathrm{C}$ for $20 \mathrm{~min}$. Two and a half microliters of the PI mix was then added to the mixture, and the resulting cell suspension was held at $4^{\circ} \mathrm{C}$ in the absence of light for $15 \mathrm{~min}$. Flow cytometry was performed using a BD FACS Caliber instrument (BD Biosciences, San Jose, USA).

\section{Conclusion}

In summary, we have successfully synthesized a novel series of CA-4 analogues bearing a 3'-O-substituted carbonic ether moiety and evaluated their antitumor activities against four tumor cell lines using a WST-1-based cytotoxicity assay. The results revealed that all of the synthesized compounds exhibited high levels of antitumor activity, with most of the compounds exhibiting similar levels of bioactivity to CA-4. Compound CA-4E, in particular, showed much higher levels of bioactivity than CA-4, with $\mathrm{IC}_{50}$ values in the range of 1 to $180 \mathrm{nM}$. For this reason, CA- $4 \mathrm{E}$ was selected as the best representative of the synthesized compounds to investigate the antitumor mechanism of these analogues by assessing the effect of CA-4E on the cell cycle and apoptosis. The cell cycle results demonstrated that CA-4E induced time- and dose-dependent G2/M arrest in the same way as CA-4, although the effect of CA-4E was more pronounced than that of CA-4. Furthermore, the apoptosis data showed that CA-4E induced cellular apoptosis in a dose-dependent manner. Taken together, these results suggest that the anticancer activity of CA- $4 \mathrm{E}$ is worthy of further study, with CA- $4 \mathrm{E}$ representing a potential new anticancer drug candidate.

\section{Additional files}

\section{Additional file 1: Synthetic route of CA-4 and target compounds 6-14. This file contains the synthetic route to $C A-4$ and the novel derivatives 6-14 which were synthesized from 3,4,5-trimethoxyphenylacetic acid (1) and 3-hydroxy-4-methoxybenzaldehyde (2). \\ Additional file 2: Experimental details of the preparation and data for CA-4 and its derivatives 6-14. This file includes the experimental procedures CA-4 and target compounds 6-14 and their spectroscopic data, as well as the copies of ${ }^{1} \mathrm{H}-\mathrm{NMR}$ and ${ }^{13} \mathrm{C}-\mathrm{NMR}$.}

\section{Competing interests}

The authors declare that they have no competing interests.

\section{Authors' contributions}

The current study represents the outcome of constructive discussions between all of the authors. SL and LH offered the necessary guidance to MM to successful carrying out the synthesis, characterization and bioactivity evaluation experiments. JM assisted with the synthetic work. All of the authors have read and approved the final manuscript.

\section{Acknowledgements}

This work was supported by the National Natural Science Foundation of China (Grant no. 81274031). We kindly thank Prof. Jian Zhang (Immune Pharmacological Institute, School of Pharmaceutical Sciences, Shandong University) for her assistance with the biological activity research.

Received: 21 August 2013 Accepted: 25 November 2013 Published: 5 December 2013

\section{References}

1. Pettit GR, Singh SB, Hamel E, Lin CM, Alberts DS, Garcia-Kendall D: Isolation and structure of the strong cell growth and tubulin inhibitor combretastatinA-4. Experientia 1989, 45:209-211.

2. Patterson DM, Rustin GJS: Vascular damaging agents. Clin Oncol 2007, 19:443-456.

3. Lippert JW III: Vascular disrupting agents. Bioorg Med Chem 2007, 15:605-615.

4. Hinnen P, Eskens F: Vascular disrupting agents in clinical development. Brit J Cancer 2007, 96:1159-1165.

5. Chang JY, Hsieh HP, Chang CY, Hsu KS, Chiang YF, Chen CM, Kuo CC, Liou JP: 7-Aroyl-aminoindoline-1-sulfonamides as a novel class of potent antitubulin agents. J Med Chem 2006, 49:6656-6659. 
6. Lawrence NJ, Ghani FA, Hepworth LA, Hadfield JA, McGown AT, Pritchard RG: The synthesis of (E) and (Z)-combretastatins A-4 and a phenanthrene from Combretum caffrum. Synthesis 1999, 9:1656-1660.

7. Liou JP, Chang JY, Kuo FM, Chang CW, Tseng HY, Wang CC, Yang YN, Chang JY, Lee SJ, Hsieh HP: Concise synthesis and structure -activity relationships of combretastatin A-4 analogues, 1-aroylindoles and 3-aroylindoles, as novel classes of potent antitubulin agents. J Med Chem 2004, 47:4247-4257.

8. Liou JP, Chang JY, Chang CW, Chang CY, Mahindroo N, Kuo FM, Hsieh HP: Synthesis and structure-activity relationships of 3-amino-benzophenones as antimitotic agents. J Med Chem 2004, 47:2897-2905.

9. Liou JP, Chang CW, Song JS, Yang YN, Yeh CF, Tseng HY, Lo YK, Chang YL, Chang CM, Hsieh HP: Synthesis and structure-activity relationship of 2-aminoben-zophenone derivatives as antimitotic agents. J Med Chem 2002, 45:2556-2562.

10. Woods JA, Hadfield JA, Pettit GR, Fox BW, McGown AT: The interaction with tubulin of a series of stilbenes based on combretastatinA-4. Brit J Cancer 1995, 71:705-711.

11. Lawrence NJ, Hepworth LA, Rennison D, McGown AT, Hadfield JA: Synthesis and anticancer activity of fluorinated analogues of combretastatin A-4. J Fluorine Chem 2003, 123:101-108.

12. Kong Y, Grembecka J, Edler MC, Hamel E, Mooberry SL, Sabat M, Rieger J, Brown ML: Structure-based discovery of a boronic acid bioisostere of combretastatin A-4. Chem Biol 2005, 12:1007-1014.

13. Pettit GR, Rhodes MR, Herald DL, Hamel E, Schmidt JM, Pettit RK Antineoplastic agents: 445: synthesis and evaluation of structural modifications of (Z)-and (E)-combretastatin A-4. J Med Chem 2005 48:4087-4099

14. Chaplin DJ, Horsman MR, Siemann DW: Current development status of small-molecule vascular disrupting agents. Curr Opin Investig Drugs 2006, 7:522-528.

15. Kamal A, Mallareddy A, Ramaiah MJ, Pushpavalli SNCVL, Suresh P, Kishor C, Murty JNSRC, Rao NS, Ghosh S, Addlagatta A, Pal-Bhadra M: Synthesis and biological evaluation of combretastatin-amidobenzothiazole conjugates as potential anticancer agents. Eur J Med Chem 2012, 56:166-178.

16. Liu YQ, Li XJ, Zhao CY, Nan X, Tian J, Morris-Natschke SL, Zhang ZJ, Yang $X M$, Yang L, Li LH, Zhou XW, Lee KH: Synthesis and mechanistic studies of novel spin-labeled combretastatin derivatives as potential antineoplastic agents. Bioorg Med Chem 2013, 21:1248-1256.

17. Pettit GR, Singh SB, Boyd MR, Hamel E, Pettit RK, Schmidt JM, Hogan F: Antineoplastic agents: 291: isolation and synthesis of combretastatins A-4, A-5, and A-6. J Med Chem 1995, 38:1666-1672.

18. Gaukroger K, Hadfield JA, Hepworth LA, Lawrence NJ, McGown AT: Novel syntheses of cis and trans isomers of combretastatin A-4. J Org Chem 2001, 66:8135-8138.

19. Ngamwongsatit P, Banada PP, Panbangred W, Bhunia AK: WST-1-based cell cytotoxicity assay as a substitute for MTT-based assay for rapid detection of toxigenic Bacillus species using $\mathrm{CHO}$ cell line. J Microbiol Meth 2008, 73:211-215

20. Nandy P, Banerjee S, Gao H, Hui MBV, Lien EJ: Quantitative structure-activity relationship analysis of combretastatins: a class of novel antimitotic agents. Pharm Res 1991, 8:776-781.

21. Gambari R, Terada M, Bank A, Rifkind RA, Marks PA: Synthesis of globin mRNA in relation to the cell cycle during induced murine erythroleukemia differentiation. Proc Natl Acad Sci 1978, 75:3801-3804.

\section{Publish with ChemistryCentral and every scientist can read your work free of charge \\ "Open access provides opportunities to our colleagues in other parts of the globe, by allowing anyone to view the content free of charge." \\ W. Jeffery Hurst, The Hershey Company.}

- available free of charge to the entire scientific community

- peer reviewed and published immediately upon acceptance

- cited in PubMed and archived on PubMed Central

- yours - you keep the copyright

Submit your manuscript here:

http://www.chemistrycentral.com/manuscript/<smiles>c1ccccc1</smiles>

Chemistry Central 